LETTERS

If you have a burning desire to respond to a paper published in $E M$, why not make use of our "rapid response" option? Log on to our web site (www.emjonline. com), find the paper that interests you, and send your response via email by clicking on the "eletters" option in the box at the top right hand corner. Providing it isn't libellous or obscene, it will be posted within seven days. You can retrieve it by clicking on "read eletters" on our homepage.

The editors will decide as before whether to also publish it in a future paper issue.

\section{Changing patterns in the care of emergencies in the community: workload of the Westcountry Ambulance Service 1994-2001}

The acute work of the ambulance service is of two sorts. Emergencies result from 999 telephone calls usually made by members of the public. Urgent transfers follow a request by a general practitioner (GP) or other health care professional to take a patient to hospital. In recent years there has been a large increase in emergency calls to the ambulance service. This has not been associated with a reduction in severity of illness, as judged by patient disposal from the A\&E department. ${ }^{1}$ We felt that some of the increasing emergency calls was caused by a reduction in urgent calls and tested this hypothesis by examining the workload of the Westcountry Ambulance Service for each financial years $1994 / 5$ to 1999/2000.

Emergency ambulance calls increased by $59.4 \%$ from 79031 in $1994 / 5$ to 125161 in $2000 / 1$ and in the same time urgent calls have decreased by $8.5 \%$ from 59118 to 54007 Urgent calls fell from $42.8 \%$ to $30.2 \%$ of the total acute workload. The increase in the emer-

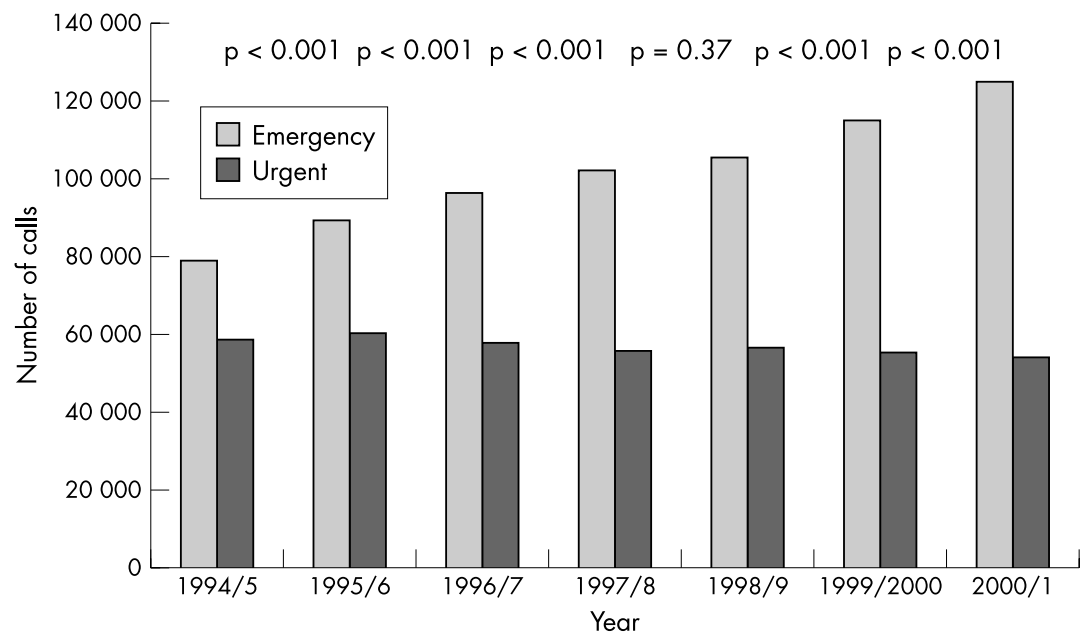

Figure 1 Emergency and urgent calls to Westcountry Ambulance Service, 1994-2001. gency calls as a proportion of the total calls year by year was compared by $\chi^{2}$ testing. This yearly increase is statistically highly significant except between 1997/8 to 1998/9. These results are shown graphically in figure 1.

You would expect a rising emergency workload to cause an increase in both 999 calls and in calls to the GP that would result in more urgent transfers. This has not happened and it seems that there has been a transfer of some work from the GP services to the ambulance service. Some $10.9 \%$ of the increase in emergency calls can be accounted for by a decreased number of urgent calls.

We have not investigated the reasons for this change in practice but emphasis on the early recognition and treatment of severe asthma, myocardial infarction, and meningococcal disease may have prompted patients to call for an ambulance rather than phone their GP.

Another factor may be changes to the GP contract in 1995. GPs no longer have to visit all who call but can use their clinical judgement and can telephone for an emergency ambulance without seeing the patient or can advise the patient or carer to do so. In particular, the change in contract has stimulated the growth of GP cooperatives to cover out of hours work. These have resulted in a shift away from home visiting towards telephone advice and patients visiting the cooperative's base. ${ }^{2}$ NHS Direct did not start in this area until March 1999 and so does not seem to be an important factor.

Much of the transferred workload may be justified but it has a cost. For the ambulance service, urgent calls have to arrive at hospital within half an hour of the time specified by the GP whereas emergency calls have to be A and 19 minutes for category B. Emergency patients need to be assessed by a paramedic whereas for urgent calls, much of the assessment will have been done by the GP. For the hospital, patients arriving as a result of urgent calls will be seen by the admitting team. The same patient arriving as a result of a 999 call will need to be assessed by an A\&E doctor before referral to the admitting team and this is putting additional pressure on A\&E departments. responded to within eight minutes if category Accident and Emergency Department, Derriford
Hospital, Plymouth PL6 8DH, UK

G Bryce

Accident and Emergency Department Taunton and Somerset Hospital, Taunton and Westcountry Ambulance Service

Correspondence to: Dr H R Guly; henry.guly@phnt.swest.nhs.uk

\section{References}

1 Mann C, Guly H. Is the emergency (999) ambulance service being misused? Retrospective analysis. BM 1998;316:437-8.

2 Jessop L, Beck I, Hollins L, et al. Changing the pattern out of hours: a survey of general practice cooperatives. BM 1997;314:199-200.

\section{Prehospital thoracotomy}

We were interested to the read case report by Wright and Murphy of a prehospital thoracotomy. ${ }^{1}$ We use a rather different interpretation of the evidence to guide our approach to this problem.

We differ on a number of points. If an immediate prehospital thorocotomy is indicated we have learned from the nine survivors that have been achieved within the London HEMS system, that asystole is not an indicator of an unsurvivable injury. We would also disagree with the time limits given for this intervention, and would only recommend a prehospital thorocotomy when the "downtime" is less than 10 minutes-30 minutes of zero cardiac output makes this, or any other intervention, futile. ${ }^{2}$ It is also incorrect that all survivors of this procedure are neurologically intact-it should be expected that there will be a level of brain injury associated with "near death". There is insufficient evidence to be definite about the incidence of disability in survivors but current evidence would suggest that prehospital thorocotomy has about the same long term disability as emergency room thorocotomy (around 10\%).

G Davies, D Lockey, T Coats Helicopter Emergency Medical Service, Royal London Hospital, London, UK

Correspondence to: Dr D Lockey, Department of Anaesthesia, Frenchay Hospital, Frenchay Park Road, Bristol BS16 1LE UK. david.lockey@north-bristol.swest.nhs.uk

\section{References}

1 Wright KD, Murphy K. Cardiac tamponade: a case of kitchen floor thoracotomy. Emerg Med J 2002; 19:587-8

2 Coats TJ. Keogh S, Clark H, et al. Prehospital resuscitative thoracotomy for cardiac arrest after penetrating trauma: rationale and case series. J Trauma 2001:50:670-3.

\section{Author's reply}

I thank Davies and colleagues for their interest and comments. I should like to address some of their questions.

This was a case report. ${ }^{1}$ It did not attempt to lay down protocols for use based on such a limited evidence base. The important learning points from this case should be: 
(1) The simple technique and the lack of specific cardiothoracic instruments or expertise.

(2) The fact that spontaneous motor activity and evidence of cerebration may occur in these patients once cardiac output is restored.

(3) Patients should be triaged to this procedure as a large number of non-survivors will lead to a lack of confidence in the procedure-we should aim not to exclude any cardiac tamponades.

I agree with the authors that 30 minutes is a long time to be without cardiac output. The ideal of 10 minutes from time of arrest is certainly where we should aim but response times and lack of reliable timing of arrest in some circumstances may make this an unobtainable goal. Asystole is not a uniform predictor of death/disability but its presence is certainly associated with a significantly worse outcome and thoracotomy in this group will lead to a large number of non-survivors. ${ }^{2}$ Evidence in this area is very limited. Initially evidence from the HEMS group said there was no value in prehospital thoracotomy, ${ }^{3}$ this view point has now changed. ${ }^{4}$ We must keep an open mind and continue to consider how penetrating injury is best managed.

K D Wright

Royal Surrey County Hospital, Guildford, Surrey, UK

kwright@doctors.org.uk

\section{References}

1 Wright KD, Murphy K. Cardiac tamponade: a case of kitchen floor thoracotomy. Emerg Med J 2002; 19:587-8.

2 Batistella FD, Nugent W, Owings JR, et al Field triage of the pulsless trauma patient. Arch Surg 1999;134:742-5.

3 Purkiss SF, Williams M, Cross FW, et al. Efficacy of urgent thoracotomy for trauma in patients attended by a helicopter emergency medical service. J R Coll Surg Edinb 1994;39:289-91.

4 Coats TJ, Keogh S, Clark H, et al. Prehospital resuscitative thoracotomy for cardiac arrest after penetrating trauma. Rationale and case series. J Trauma 2001;50:670-3.

\section{Use of emergency department ultrasound in the diagnosis and early management of femoral fractures}

We describe two cases illustrating the use of bedside ultrasonography in the trauma room, to confirm femoral fracture, and to guide accurate placement of femoral nerve block

\section{Case 1}

A 13 year old boy was brought to the emergency department (ED) by ambulance. He was undergoing leg lengthening surgery and had an external fixation device attached to his left femur. He had fallen onto his left knee at school, with subsequent pain and inability to bear weight. There was a tender swelling over the lateral supracondylar area of his left femur, with severe pain on minimal movement. Bedside ultrasonography in the ED was used to confirm the clinical suspicion of a distal femoral fracture. Ultrasonography was then used to image the anatomy of the femoral vessels in the left groin permitting identification of the correct location for placement of a femoral nerve block.

\section{Case 2}

A 39 year old female pedestrian was brought to the ED by ambulance having been struck by a car while crossing a road. She was alert and complained only of pain above her right knee. Her vital signs were stable. After major truncal injury had been excluded, including the use of focused assessment by sonography in trauma (FAST), ultrasound imaging was used to confirm a distal femoral fracture (fig 1). The patient complained of severe pain despite large doses of morphine. Again ultrasound was used to locate the correct position for femoral nerve block (fig 1) providing sufficient analgesia to permit application of a traction splint and subsequent transfer for definitive radiographs.

Bedside ultrasonography is being used increasingly by emergency physicians and trauma surgeons in the ED. The FAST scan has become common practice in many trauma centres and has been shown to be accurate in detecting intraperitoneal haemorrhage. ${ }^{1}$ The use of ultrasound in the diagnosis of long bone fracture in pregnancy has also been described. ${ }^{2}$ Although ultrasound has been used to guide placement of regional nerve blocks electively, there are no reports of this use in the ED setting.

The cases presented illustrate how ultrasound can be used to help confirm the clinical suspicion of long bone fracture in the trauma or resuscitation room. Often the trauma patient may be haemodynamically too unstable for transfer to the radiology department, or there may be delays in obtaining limb radiographs. Confirmation of femoral fracture permits early planning for traction splint application and contributes to the resuscitative process.

The accurate placement of a femoral nerve block in this clinical setting also offers significant benefits for the patient. The traditional method of using a nerve stimulator to locate the femoral nerve can be extremely painful for the awake patient with a femoral fracture (personal observation), yet the blind introduction of local anaesthetic into the femoral region risks ineffective nerve block. Ultrasound offers a non-invasive, painless method of identifying the local anatomy, specifically the femoral vein and artery. The introduction of local anaesthetic lateral to the femoral

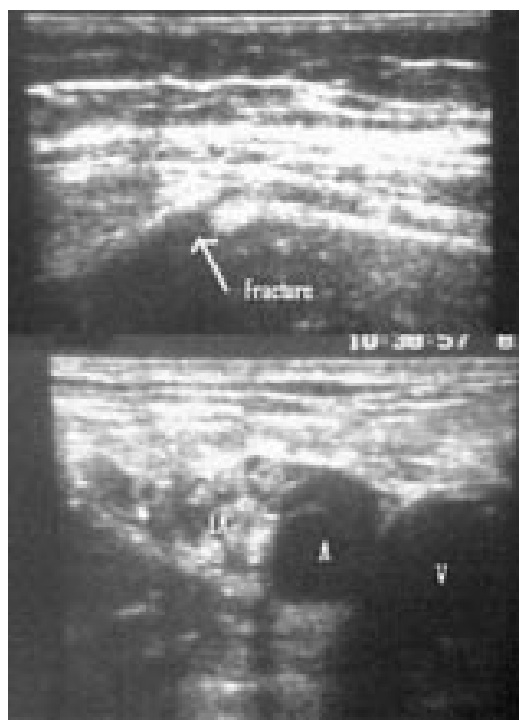

Figure 1 Sonograms demonstrating distal femoral fracture (top); and outlining femoral vein $(V)$, femoral artery $(A)$, and demonstrating introduction of local anaesthetic (LA) around femoral nerve (below). artery can then be visualised directly, increasing the likelihood of effective block.

P Atkinson

Emergency Department, Addenbrooke's Hospital Cambridge CB2 2QQ, UK

R Lennon

Emergency Department, Royal North Shore Hospital, Sydney, St Leonards, Australia

Correspondence to: Dr P Atkinson; pjatkinson@doctors.org.uk

\section{References}

1 Nordenholz KE, Rubin MA, Gularte GG , et al. Ultrasound in the evaluation and management of blunt abdominal trauma. Ann Emerg Med 1997;29:357-66.

2 Watson NA Ferrier GM. Diagnosis of femoral shaft fracture in pregnancy by ultrasound. J Accid Emerg Med $1999 ; 16: 380-1$

3 Marhofer P, Schrogendorfer K, Wallner T, et al. Ultrasonographic guidance improves sensory block and onset time of three-in-one blocks. Anesth Analg 1997;85:854-7.

\section{Transthoracic echocardiography during cardiac arrest due to massive pulmonary embolism}

I read with interest the case report by MacCarthy et al ${ }^{1}$ describing the use of transthoracic echocardiography during cardiac arrest due to massive pulmonary embolism (PE). Such cases raise the question of whether thrombolysis could be used routinely during all non-traumatic cardiac arrests, not just those known to be caused by PE.

Up to $70 \%$ of cardiac arrests have thrombosis (PE or myocardial infarction) as their underlying cause. ${ }^{2}$ Thrombolysis is of verified therapeutic benefit in both these conditions. Bottiger has prospectively studied administration of recombinant tissue plasminogen activator (r-tPA) in patients suffering out of hospital cardiac arrest. ${ }^{2}$ Compared with controls patients who received thrombolysis were significantly more likely to have return of spontaneous circulation and survive to admission to a coronary intensive care. There was no significant difference in survival to discharge, although numbers were very small. Several retrospective studies of out of hospital arrests of all causes have shown similar results.

Administration of thrombolysis not only treats the direct cause of the cardiac arrest, but it has also been shown to improve blood flow in the microvascular circulation of the brain during the post-arrest period. ${ }^{3}$ This may account for the excellent neurological status of the survivors in several of the studies.

With the introduction of single bolus thrombolytic agents, administration of thrombolysis during cardiac arrest would be a rapid, simple procedure. On the basis of the current evidence however, thrombolysis could not be recommended as a routine treatment in all cardiac arrests, but it should be considered on a case by case basis by the arrest team leader. Large randomised controlled trials are needed to provide a definitive answer to this important clinical question. Such a study, led by Bottiger, is due to start in Germany later this year (2002) (personal communication) and its results are eagerly awaited.

P Knowles Leighton Hospital, Middlewich Road, Crewe CW1 4QJ, UK; drpknowles@aol.com

\section{References}

1 MacCarthy P, Worrall A, McCarthy G, et al. The use of transthoracic echocardiography to 
guide thrombolytic therapy during cardiac arrest due to massive pulmonary embolism. Emerg Med J 2002; 19:178-9.

2 Bottiger BW, Bode C, Kern S, et al. Efficacy and safety of thrombolytic therapy after initially unsuccessful cardiopulmonary resuscitation: a prospective clinical trial. Lancet 2001;357:1583-5.

3 Fischer M, Bottiger BW, Popov-Cenic S, et al. Thrombolysis using plasminogen activator and heparin reduces cerebral no-reflow after resuscitation from cardiac arrest: an experimental study in the cat. Intensive Care Med 1996:22:1214-23.

\section{BOOK REVIEWS}

\section{Emergency ophthalmology: a rapid treatment guide}

Edited by K C Chern. (Pp 297; £44.00). McGraw Hill, New York, 2002. ISBN 0-07-137325-X

Pardon the pun, but ophthalmology is a very visual topic, so any book that aims to help the reader identify and treat eye emergencies relies on liberal use of colour photographs to permit rapid correlation between the patient in front of you and the relevant chapter. In this respect, Emergency ophthalmology does not disappoint. Furthermore, the editor, himself an assistant professor in the specialty in Boston, has drawn on a wide and expert body of authors to add authoritative guides to the immediate management of many common and not so common eye emergencies. A cynic might observe that none of the authors is himself an emergency physician, but in reality this is of little consequence-can you honestly say you aren't relieved to refer horrendous eye problems to someone who knows more about it than you?

The structure of the book is logical. A detailed summary of the anatomy of the eye and orbit, together with a reminder of how to examine the visual system properly, leads into a series of well illustrated chapters that take each component of the eye and orbit in turn and give clear details regarding the management of a wide range of pathology. Like any decent picture book, it is a pleasure just to flick through the colour photographs even without a patient to treat.
Some sections of this book are obviously more relevant to emergency medicine than others. In particular, the (brief) sections dealing with squints and some of the more esoteric visual tests available struggle to hold the reader's interest. There is also the issue of this being an American text, with the usual differences in drug nomenclature and certain aspects of ongoing care, but it is quite clear where these occur and there is no great problem in translating the information to UK practice.

There is always a sting in the tail with books that rely heavily on colour illustrations to make them worthwhile-the cost. I couldn't find any web site that sells this volume for less than $£ 44$, which makes it a departmental investment, and to be fair, there would be little point in buying this book for individual use. Having said that, this compact and very readable book contains a wealth of helpful information and would be a useful addition to any library.

D A Kilroy

Accident and Emergency Department, Northern General Hospital, Sheffield, UK

\section{Neurological emergencies, 3rd edn}

R A C Hughes, editor. (£35.00). BM Books, 2001. ISBN 0-7279-1405-7.

Neurological emergencies are comparatively rare but can have disastrous consequences if missed or mismanaged. Neurology terrifies many SHOs and even the most experienced A\&E specialist is likely to feel nervous at the thought of a patient with myasthenic crisis or cerebral malaria. A text providing up to date, practical information on the diagnosis and immediate management of acute neurological emergencies would therefore be a useful addition to any emergency department library.

This book covers all the neurological emergencies likely to present to the emergency department. The pathophysiology of each condition is described in detail in each chapter, although the sections on acute management are often shorter and vaguer than I would like. The chapters on traumatic brain injury and tonic-clonic status epilepticus are particularly good and obviously written by clinicians used to managing acute patients Similarly, the chapters on acute visual loss, acute behavioural disturbances, cerebral infection, and raised intracranial pressure are all interesting and contain useful information on differential diagnosis and treatment. However, the chapter on acute spinal cord compression suffers from having too much detail on different surgical procedures and not enough on immediate assessment and management. Additionally, the first chapter on medical coma is, to be blunt, poor. I suspect that while its author may be an eminent neurologist, it is a long time since they saw an acute patient. A lot of the information, especially on poisoning, is outdated and some of the management recommendations are rather suspect.

I was disappointed that apart from the chapters on traumatic brain injury and acute stroke, the other chapters are practically word for word the same as in the second edition. The cover of the book promises it "has been thoroughly revised and updated ..." however there is not enough evidence of this to make it worth buying the third edition if you already have the second edition.

Despite the above criticisms, overall the book is interesting, and the contributions well written. It is a useful, concise reference text to have in the department and is particularly good for preparing teaching sessions or revising for the MRCS (A\&E) or FFAEM exam as all the necessary information about pathophysiology, differential diagnosis, and investigation is there. I would recommend it to A\&E specialists to be read at their leisure. However, it is not a practical handbook and not something you would consult when faced with an acutely sick patient.

Carole Libetta

Hope Hospital, Manchester, UK

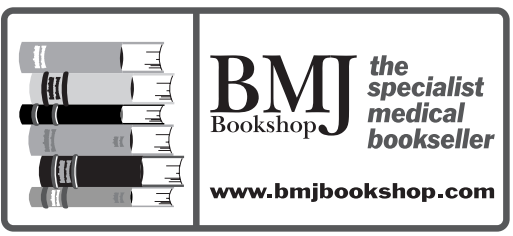

